\title{
Molecular pathways linking metabolic inflammation and thermogenesis
}

\author{
G. Solinas
}

Laboratory of Metabolic Stress Biology, Division of Physiology, Department of Medicine, University of Fribourg, Fribourg, Switzerland

Address for correspondence: Dr G Solinas, Ph.D., Laboratory of Metabolic Stress Biology, Division of Physiology, Dept. of Medicine, University of Fribourg, Chemin du Musée 5, $\mathrm{CH}-1700$ Fribourg, Switzerland.

E-mail: giovanni.solinas@unifr.ch

\begin{abstract}
Summary
Obesity is caused by chronic positive energy balance because of higher energy intake relative to energy expenditure. Thermogenesis, the capacity of an organism to produce heat, is an important component of energy expenditure. Thus targeting the molecular mechanisms controlling thermogenesis could be an effective strategy for the prevention or treatment of obesity. Thermogenesis is modulated by three major factors: environmental temperature, nutrient quantity and quality, and by systemic inflammation. Obesity is now recognized to be a state of chronic low-grade systemic inflammation, which has been proposed to play a major role in the pathogenesis of obesity and obesity-associated diseases. This review discussed the molecular pathways that are recruited during metabolic inflammation and that are also implicated in the control of thermogenesis and energy balance. It emerges that the complex signalling network recruited during metabolic inflammation exerts a balanced action on the modulation of thermogenesis and energy balance, with some pathways promoting weight gain whereas other pathways have opposite actions. It is thus concluded that immunomodulation of metabolic inflammation, rather than an anti-inflammatory intervention aiming at its suppression, may be a more promising strategy to increase thermogenesis for the treatment or prevention of obesity and its associated diseases.
\end{abstract}

Keywords: Cytokines, IKK, JNK, MAPK, PI3K.

\section{Innate immunity and thermogenesis: basic concepts}

Obesity is caused by chronic positive energy balance resulting from a higher energy intake relative to energy expenditure. Understanding the molecular mechanisms controlling energy balance is thereby fundamental to the development of novel interventions for the treatment or prevention of obesity. Homeotherm organisms, including humans and laboratory rodents, dissipate a large proportion of their ingested food energy to the environment in the form of heat (1). This capacity of living organisms to generate heat is generally referred to as thermogenesis (2). Thermogenesis is variable among different individuals and is modulated by environmental factors (2). There are essentially three major environmental factors that potently influence thermogenesis: environmental temperature (e.g. cold-induced thermogenesis), food quantity and quality (e.g. diet-induced thermogenesis), and systemic inflammation in response to infection or tissue damage (e.g. fever) $(2,3)$. Thermogenesis is chiefly controlled by the sympathetic nervous system (SNS) and depends on $\beta$-adrenergic receptors $(4,5)$, which mediate the effects of norepinephrine and other catecholamines $(3,6,7)$. Increased norepinephrine turnover was reported in the heart, white adipose tissue (WAT), and brown adipose tissue (BAT) in response to thermogenic stimuli like diet and cold $(8,9)$. Binding of catecholamines to brown adipocyte $\beta$-adrenergic receptors activates a thermogenic programme including induction of lipolysis and uncoupling protein (UCP)-1 activity and gene expression 


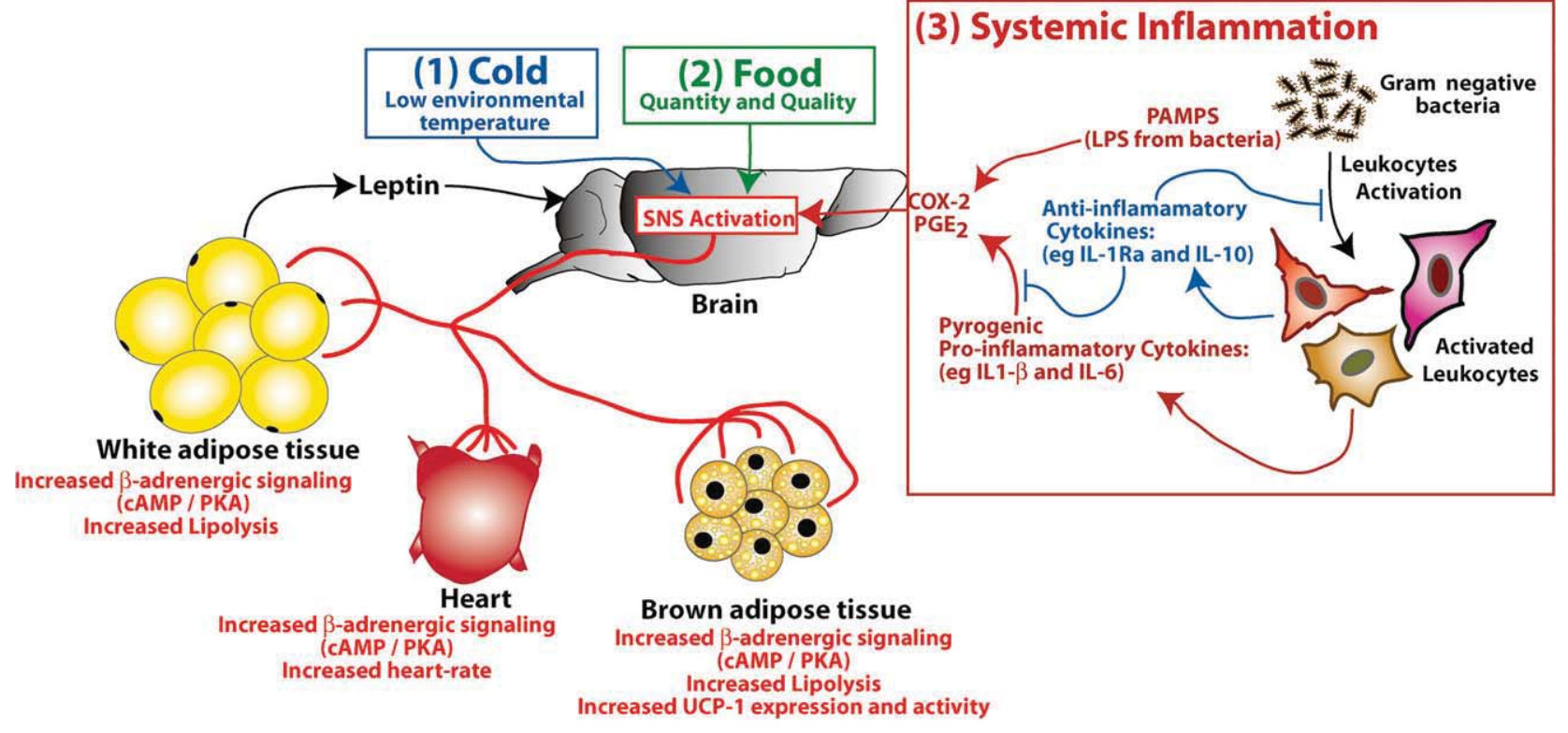

Figure 1 Essential elements in the regulation of thermogenesis. Thermogenesis is modulated essentially by three factors: (i) environmental temperature; (ii) food quality and quantity; and (iii) systemic inflammation. It is well established that the induction of thermogenesis by cold and diet depends on the sympathetic nervous system (SNS). Increased catecholamine turnover was observed in brown adipose tissue and in the heart in response to cold and cafeteria diet, and in retroperitoneal white adipose tissue in response to dietary glucose or fructose. Some studies indicate that the immune system also modulate thermogenesis via the sympathetic nervous system. Systemic inflammation can lead to either fever or hypothermia, depending on the experimental conditions. The thermogenic outcome of systemic inflammation depends on the balanced action of pyrogenic cytokines (e.g. interleukin [IL]-1ß, and IL-6) and antipyrogenic/anti-inflammatory cytokines (e.g. IL-1Ra and IL-10). Leptin signalling is known to be required for an efficient induction of thermogenesis by cold and food. CAMP, cyclic adenosine monophosphate; COX-2, cyclooxygenase 2; LPS, lipopolysaccharides; PAMPs, pathogen-associated molecular patterns; PGE 2, prostaglandin E2; PKA, protein kinase A; UCP-1, uncoupling protein.

(6,7). $\beta$-adrenergic signalling in white adipocytes and cardiomyocytes is likely to play an important role in sustaining thermogenesis by providing fatty acid substrates from lipolysis that are transported to the BAT via an increased blood flow (Fig. 1).

The adipocyte-derived hormone leptin plays a major role in sustaining thermogenesis (Fig. 1). Indeed, mutant mice with defective leptin signalling display dramatically decreased sympathetic tone in BAT $(10,11)$, in addition to showing impaired thermogenic response to cafeteria diet (12) and cold intolerance (13).

The SNS and more generally the nervous system are tightly interconnected with the immune system. These systems influence each other in a bidirectional manner and share similar molecular mechanisms (14). Indeed, on the one hand, the SNS is known to play a powerful action on white blood cells to control immunity (15), and it has also been shown that leukocytes themselves produce catecholamines to modulate the immune reaction $(16,17)$. Furthermore, macrophage-mediated immunity and reactive oxygen species production have been shown to be modulated by the UCP-2, a protein with high sequence similarity to UCP-1 (18). On the other hand, the innate-immune system exerts a powerful control on the SNS and thermogenesis. Fever can be seen as a paradigm of such neuro- immune interaction where pathogens activate leukocytes and other cells leading to increased levels of proinflammatory mediators whose action on the central nervous system results in increased core body temperature (Fig. 1). The precise cellular and molecular mechanism controlling fever is still not completely understood and different mechanisms are recruited in different models. However, three central molecular mediators of the febrile response to exogenous pyrogens such as bacterial endotoxin have been identified: the toll-like receptor 4 (TLR-4), the pyrogenic cytokines and the pyrogenic prostaglandins (19-22). Pathogen-associated molecular patterns (PAMPs) are sensed by specific receptors such as TLR-4, the sensor of bacterial lipopolysaccharides (LPS). Once activated, TLR-4 receptors lead to the activation of different kinases including mitogenactivated protein kinases (MAPK) and the inhibitor of kappa-B kinase (IKK) complex, which are responsible, respectively, for the activation of the transcription factors activator protein 1 (AP-1) and nuclear factor kappa-B (NF$\mathrm{kB})$, leading to increased expression of inflammatory mediators (23). Pyrogenic cytokines, most notably the interleukins (IL) IL-1 and IL-6, are the primary endogenous pyrogens and are produced in response to either PAMPs or damageassociated molecular patterns (DAMPs) (19-22). Both endogenous pyrogenic cytokines and exogenous pyrogens 
(e.g. LPS) induce the expression of the gene encoding for the cyclooxygenase 2 (COX-2), the enzyme responsible for the production of pyrogenic and inflammatory prostaglandins such as $\mathrm{PGE}_{2}$ (prostaglandin E2) (19-22). Overall, LPS and pyrogenic cytokines can induce a complex physiological response leading to higher core body temperature by a mechanism that depends on COX-2 activity $(24,25)$ and that involves increased thermogenesis partly because of the activation of SNS $(26,27)$ (Fig. 1).

It is important to consider that, in addition to fever, systemic inflammation can also cause hypothermia depending on the experimental conditions $(28,29)$. Indeed, fever and hypothermia are both clinical signs of sepsis. It is well established in mouse models that the effects of LPS on core temperature depends on dose, route of administration and environmental temperature $(28,29)$. Indeed, intraperitoneal injection of a low dose of LPS $\left(50 \mu \mathrm{g} \mathrm{kg}^{-1}\right)$ is known to cause fever without hypothermia, whereas a higher dose of LPS (2.5 mg kg-1) causes a 'multiphase' response with hypothermia preceding fever, and finally, a lethal dose of LPS (10 mg kg-1) was reported to induce sustained hypothermia (28). Furthermore, a hypothermic phase preceding fever was also observed in the caecal-ligation puncture model, which reproduces sepsis (28). Our current understanding of the mechanisms of hypothermia in systemic inflammation is poor compared with our understanding of fever. Systemic inflammation-induced hypothermia may be at least in part explained by increased heat loss, although the precise mechanism remains to be established and suppression of thermogenesis may also play an important role. Overall, it is evident that during systemic inflammation, several cytokines and other signalling molecules are released: some cytokines display clear pyretic effects (e.g. IL-1, and IL-6) whereas others are antipyretic (e.g. IL-1Ra and IL-10) (30) (Fig. 1). Thus, the final effect of systemic inflammation on body core temperature and thermogenesis is likely the outcome of the integrated action of the specifically recruited signalling network. Interestingly, the pro-inflammatory cytokine tumour necrosis factor (TNF) $\alpha$ was reported to display both pyretic and antipyretic activity depending on the specific model in which its action is tested. TNF $\alpha$ can be considered a pyrogen as intravenous injection of TNF $\alpha$ causes fever in different species by a mechanism involving SNS-dependent induction of thermogenesis (31-33). However, the pyrogenic action of TNF $\alpha$ depends on the specific experimental model as TNF $\alpha$ was also reported to act as antipyretic and promote LPS-induced hypothermia (34-36). Interestingly, one study showed an association between TNF $\alpha$-induced hypothermia and decreased sympathetic outflow to BAT (37), suggesting that at least in some conditions, TNF $\alpha$ signalling may decrease thermogenesis. Thus, considering the powerful actions of different cytokines in the regulation of SNS-mediated thermogenesis, it is possible that signal- ling pathways implicated in innate immunity may also be involved in the control of energy balance and body weight homeostasis.

\section{Obesity is a state of low-grade chronic systemic inflammation}

Obesity is an inflammatory condition characterized by elevated levels of pro-inflammatory cytokines, accumulation of leukocytes within adipose tissue and other organs, activation of macrophages in liver and fat, and activation of pro-inflammatory signalling pathways in multiple organs (38-43). Inflammation can be triggered by pathogens or by tissue damage, and although the precise mechanism causing inflammation during obesity is still under investigation, two main mechanisms have been proposed: one focused on metabolic endotoxemia and the other one on metabolic stress. Concerning the former hypothesis, it was reported that the gut microbial population is altered in obese mice independently of the diet (44), and that feeding mice on a high-fat diet (HFD) causes a state of chronic low-grade endotoxemia, which was proposed to be an initiating factor of obesity-induced inflammation (45). The second mechanism proposed to underlie metabolic inflammation focuses on metabolic stress caused by excess nutrients. During positive energy balance, excess calories are safely stored in adipocytes as triglycerides. However, when the adipose tissue expandability limit is achieved, toxic lipids accumulate in non-adipose tissues causing metabolic stress and activating pro-inflammatory signalling cascades (38-42,46-48). At the same time, the hypertrophic adipocytes die by necrosis causing leukocyte infiltration into WAT with activated macrophages accumulating around the lipid vacuole from dead adipocytes to form typical crownlike structures (49). In support for the idea of a crucial role for adipose tissue expandability in metabolic inflammation is the demonstration that a similar inflammation to the one observed in obesity models is also observed in lipodystrophic mice, where adipocyte hypertrophy and fat storage saturation are achieved in non-obese mice on a low-fat $\operatorname{diet}(49,50)$.

Overall, obesity is an inflammatory state where signals reported to exert powerful effects on thermogenesis are chronically recruited. As described earlier, acute systemic immune reactions can have powerful effects in either increasing or decreasing body core temperature depending on the specific model. Such powerful and opposing effects of the immune system on core body temperature may in part be explained by the specific signalling network recruited in the specific context. It is therefore important to note that metabolic inflammation is characterized by a distinct cytokinesignalling network. The obese adipose tissue is characterized by the accumulation of pro-inflammatory leukocytes and polarization of the local macrophage population from M2 


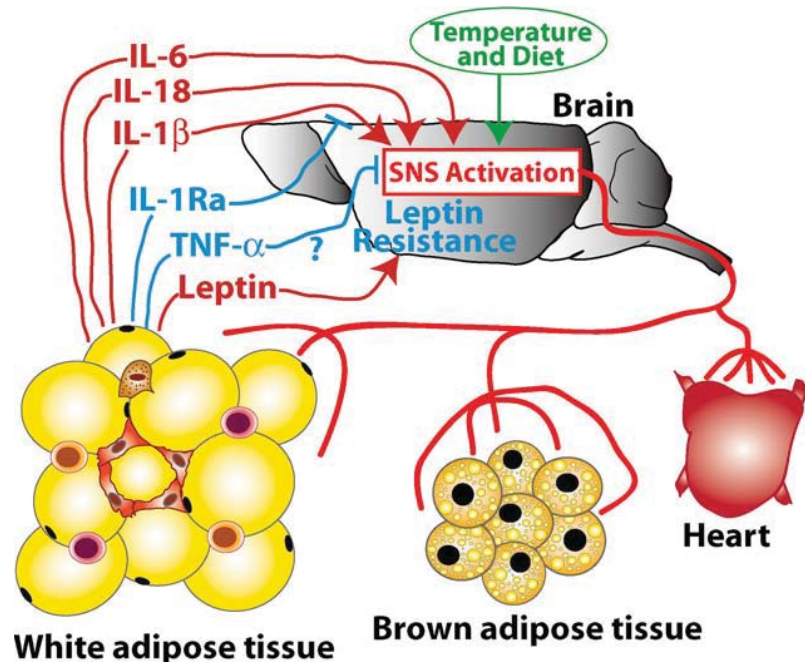

Figure 2 Possible actions of adipokines in the control of thermogenesis during obesity. The obese adipose tissue is characterized by leucocyte infiltration, a chronic low-grade induction of pro-inflammatory cytokines (e.g. tumour necrosis factor- $\alpha$ [TNF $\alpha]$, interleukin [IL]-6 and IL-1 $\beta$ ), and by increased levels of the anti-inflammatory cytokine IL-1Ra. The classical pyrogenic cytokines IL-6 and IL-1 $\beta$, as well as IL-18 were proposed to antagonize positive energy balance and to sustain thermogenesis. By contrast, evidence suggests that IL-1Ra may promote positive energy balance by suppressing sympathetic tone. Some evidence suggests that TNF $\alpha$ may also promote positive energy balance and negatively regulate thermogenesis. As indicated here, these cytokines may control thermogenesis via the sympathetic nervous system (SNS). However, possible peripheral actions should also be considered. Intact leptin signalling is known to be a basic requirement for efficient thermogenesis in response to cold and food. Thus insufficient leptin signalling (e.g. leptin resistance) may lead to defective thermogenesis promoting positive energy balance and obesity.

(typically anti-inflammatory) towards an M1 phenotype (typically pro-inflammatory) $(51,52)$. This is paralleled by a low-grade but chronic elevation of the production of proinflammatory pyrogenic cytokines, and decreased expression of the anti-inflammatory cytokine IL-10 (51,52). Despite the clear pro-inflammatory 'cytokine signature' associated with obesity, it is important to note that among the cytokines displaying the largest induction of gene expression in the obese adipose tissue one can find the IL- 1 receptor antagonist (IL-1Ra), a most powerful anti-inflammatory and antipyretic cytokine whose function is to antagonize IL-1 signalling (30,53-55) (Fig. 2).

\section{Exogenous pyrogens and pathogen-associated molecular patterns receptors in obesity- induced inflammation and thermogenesis}

PAMPs from gram-negative bacteria are most potent exogenous pyrogens, which paradoxically can also cause hypothermia depending on the experimental conditions. Gut microbiota has been identified as an environmental factor implicated in energy balance (56). The gut microbial population is altered during obesity (44), and it has been shown that HFD increases the circulating levels of LPS (45). In a study investigating the effects of metabolic endotoxemia on obesity, LPS levels were chronically elevated to the concentration observed in HFD-fed mice for 4 weeks by continuous LPS infusion using an osmotic pump (45). Strikingly, LPS-infused mice kept on low-fat diet displayed higher weight gain than control saline-infused mice on low-fat diet, with the greater weight gain being similar to mice kept on HFD. However, whereas the increased weight gain on HFD-fed mice compared with low-fat diet-fed mice was largely due to increased energy intake, in LPS-infused mice energy intake was significantly lower than HFD-fed mice and similar to the one observed in low-fat diet-fed mice. This observation suggests that chronic low-grade endotoxemia may promote feed efficiency by reducing apparent energy expenditure.

TLR-4 was identified as a major sensor for bacterial LPS, and it was proposed that TLR-4 might be a sensor for saturated free fatty acids (57). Nonetheless, the role of TLR-4 in diet-induced obesity is less obvious as different studies investigating TLR-4 loss of function in mice models of diet-induced obesity have reported different results, ranging from increased predisposition to obesity to a dramatic protection from diet-induced obesity compared with wild-type (WT) control mice (57-59). Whereas such discrepancies suggest that the impact of TLR-4 signalling on energy balance may depend on the specific experimental conditions, it should be noted that when loss of functional TLR-4 was linked to increased weight gain, this was largely due to increased food intake (57), whereas when resistance to diet-induced obesity was observed, this was explained by increased thermogenesis (58). Thus, it cannot be excluded that TLR-4 signalling might have opposing effects on food intake and thermogenesis in models of diet-induced obesity and might therefore either promote or antagonize positive energy balance depending on the specific experimental condition. Still, the precise role of TLR-4 on thermogenesis and energy balance in body weight homeostasis and obesity remains to be established.

The nucleotide-binding oligomerization domain-like receptors (NLR) are a family of intracellular PAMPs and DAMPs receptors implicated in pathogen and damage sensing (60). A study reported that mice lacking two NLR family members NOD1 and NOD2 display reduced adiposity when placed on HFD compared with WT mice (61). However, this leaner phenotype could be partially explained by increased spontaneous physical activity and decreased food intake. Thus, at this stage, it is not clear whether NOD1 and NOD2 may also play a role in the control of thermogenesis. Another NLR family member that was recently implicated in metabolic inflammation and energy balance is the NOD-like receptor NLRP-3 
(NOD-like receptor family, pyrin domain containing protein). NLRP-3 is an intracellular receptor that forms a large complex with other proteins called the inflammasome, which is implicated in sensing different PAMPs and DAMPs (62). Activation of NLRP-3 leads to the recruitment of the caspase- 1 protease via the adaptor protein ASC (apoptosisassociated speck-like protein containing a carboxy-terminal CARD), leading to proteolytic cleavage of IL-1 $\beta$ and IL-18 precursors to generate their mature forms, which are then secreted. Mutations of NLRP-3 in humans, also known as cryopyrin, were found to cause familial cold autoinflammatory syndrome, a rare genetic disease characterized by episodes of systemic inflammation and fever triggered or exacerbated by acute cold exposure $(63,64)$. Thus, such genetic condition strongly suggests that on top of the function of pathogen and damage sensor, NLRP-3 might also act as a 'cold sensor'. NLRP3 was proposed to play a major role in linking obesity-induced lipotoxicity to metabolic inflammation and insulin resistance. Indeed, mice lacking NLRP-3 display decreased inflammasome activation and improved insulin sensitivity in models of diet-induced obesity (65). However, it is important to notice that in this study, mice lacking NLRP-3 kept on HFD showed decreased epididymal fat pad weight and dramatically decreased adipocyte size and lipid accumulation in the liver compared with WT control mice. These data suggest that at least part of the beneficial effects of NLRP-3 inactivation on metabolic inflammation and insulin resistance could be the indirect consequence of decreased adiposity and ectopic lipid, suggesting a role for NLRP-3 and the inflammasome in energy balance. Consistent with this interpretation, another study showed that mice lacking either NLRP-3, the adapter ASC or caspase-1 inflammasome proteins display decreased weight gain compared with WT control mice kept on HFD (66). Mice lacking one of the essential inflammasome components (NLRP-3, ASC or caspase-1) and WT control mice displayed similar caloric intake suggesting that differences in weight gain are likely due to decreased feeding efficiency and hence to increased apparent energy expenditure of mutant mice (66). Consistently, compared with WT controls, mice lacking caspase- 1 displayed increased energy expenditure on a HFD, as measured by indirect calorimetry. These latter results are in sharp contrast with a more recent study showing a protective action of the inflammasome in the progression of diet-induced obesity, glucose intolerance and non-alcoholic fatty liver disease, by maintaining a 'healthier' gut microbiota (67). Collectively, these studies suggest that the inflammasome complex plays an important role in the control of thermogenesis and energy balance in mice models of diet-induced obesity. Overall, the interpretation of these studies is complex, and for the future, it will be important to discriminate between possible role of the inflammasome in the ecology of gut microbiota and the direct effects on thermogenesis, energy balance and glucose homeostasis.

\section{Obesity-induced inflammation and thermogenesis: possible roles for pyrogenic cytokines}

\section{Interleukin-6 and interleukin-1}

The major pyrogenic cytokines IL- 6 and IL- 1 are elevated in adipose tissue and blood during obesity and were proposed to play an important role in obesity-induced glucose intolerance. However, as IL-6 and IL- 1 activate thermogenesis during fever $(19,20)$, it is possible that IL- 6 and IL-1 could play a protective role in models of diet-induced obesity by promoting thermogenesis, thus antagonizing positive energy balance and the development of obesity. Consistent with this view is the report that mice lacking IL-6 spontaneously develop mature-onset obesity on a standard low-fat diet (68), a phenotype that was partially explained by the central effects of IL- 6 on thermogenesis $(68,69)$. However, in another study, age-related obesity was not observed in mice lacking IL-6 (70), thereby suggesting that the presence of IL-6 is not an essential requirement for body weight homeostasis. Yet, a third study reported that mice lacking IL-6 and IL-1 display increased weight gain, although this could be largely explained by increased food intake (71). IL-1 signalling was proposed to play an important role in leptin-mediated control of energy balance and thermogenesis (72). Since then, several studies have supported the concept of a role for IL-1 as a thermogenic signal implicated in the control of body weight. Indeed it has been shown that mice that do not express IL-1Ra, a most potent antagonist of IL-1 signalling, display decreased weight gain and increased energy expenditure (73). This observation was confirmed by another laboratory, which also correlated the decreased weight gain and increased energy expenditure observed in mice lacking IL1-Ra with increased sympathetic tone (74). Consistently, it was reported that mice lacking IL-1 receptor develop mature-onset obesity (75), a phenotype that was partially explained by decreased leptin sensitivity. It is important to note that IL-1Ra gene expression is markedly induced in obese WAT $(53,54)$. IL-1 $\beta$ expression is also induced in obese WAT, but to a lower extent than IL1-Ra $(53,54)$. Overall these data suggest that during obesity, decreased IL-1 signalling because of increased IL-1Ra levels may promote feed efficiency and positive energy balance (Fig. 2).

\section{Interleukin-18}

The cytokine IL-18, which like IL-1 $\beta$, is processed into its active form by the inflammasome complex, has also been implicated in the control of energy expenditure. Indeed, mice lacking IL-18 display increased feed efficiency and reduced oxygen consumption compared with WT control mice $(76,77)$. These studies on the role of IL-1 and 
IL-18 on energy balance are paradoxical with the one on the inflammasome complex described earlier, where mice lacking key inflammasome components are resistant to diet-induced obesity because of increased energy expenditure despite defective IL-1 and IL-18 processing $(65,66)$. Again, it was recently reported that the inflammasome is implicated in the control of intestinal microbiota, and that lack of inflammasome function leads to alteration of the gut microbiota predisposing to obesity (67). Thus, resolving these apparent paradoxes will be important to better understand the complex action of the inflammasome, IL-1 and IL-18 in metabolic homeostasis and thermogenesis.

\section{Tumour necrosis factor- $\alpha$}

Another pro-inflammatory cytokine whose expression is induced during obesity is TNF $\alpha$. Blocking TNF $\alpha$ signalling either using neutralizing antibodies or by genetic deletion of the TNF $\alpha$ gene or both its receptors TNFR1 and TNFR2 genes was reported to improve glucose homeostasis in rodent models of obesity without affecting body weight $(78,79)$. However, it was also reported that genetically obese $o b / o b$ mice, which also lack TNFR1 or both TNFR1 and TNFR2, display increased $\beta 3$-adrenergic receptor and UCP-1 mRNA levels in BAT, reduced brow adipose tissue apoptosis and increased number of multilocular brown adipocytes compared with ob/ob mice expressing TNFR1 (80). Furthermore, incubation of cultured brown adipocytes with TNF $\alpha$ caused decreased $\beta 3$-adrenergic receptor mRNA levels and defective cAMP (cyclic adenosine monophosphate) production in response to $\beta 3$-adrenergic receptor agonist (80). Collectively, these results suggest that TNF $\alpha$ via TNFR1 decreases $\beta 3$-adrenergic receptor signalling in BAT and thus TNFR1 could be an important negative regulator of BAT activation. Most importantly, ob/ob mice lacking TNFR1 and TNFR2 showed improved capacity to maintain core body temperature when exposed to cold $\left(4^{\circ} \mathrm{C}\right)$ compared with $o b / o b$ mice with intact TNFo signalling, thus revealing an important role for TNF $\alpha$ signalling as negative modulator of cold-induced thermogenesis (80). Interestingly, in this study, body weight was significantly reduced in TNFR-deficient female $o b / o b$ mice compared with $o b / o b$ mice expressing the TNF $\alpha$ receptors, suggesting that TNF $\alpha$ signalling may be implicated in body weight regulation. Consistent with this view, another laboratory reported that mice specifically lacking TNFR1 signalling, but expressing a functional TNFR2 were protected from diet-induced obesity, a phenotype that was explained by increased thermogenesis (81). Overall these studies on TNF $\alpha$ signalling in cold-induced thermogenesis and energy balance are consistent with the previously proposed role for TNF $\alpha$ as antipyretic and negative modulator of the SNSBAT axis during fever (34-37) (Fig. 2). Whether TNFR2 is also implicated in the control of thermogenesis and whether there is a specific crosstalk between TNFR1 and TNFR2 signalling in thermogenesis remains to be established.

\section{Ciliary neurotropic factor}

The cytokine ciliary neurotrophic factor (CNTF), which so far, was not directly implicated in metabolic inflammation, emerged for its potential as antiobesogenic drug $(82,83)$. CNTF is a pleiotropic cytokine that was identified as neuron-survival factor (84) and was later found to be an endogenous pyrogen (85), although its physiological role in systemic inflammation and fever remains to be established. During a clinical trial for the treatment of amyotrophic lateral sclerosis with recombinant CNTF it was observed that obese patients receiving CNTF significantly lost weight compared with placebo-treated patients, suggesting an important role for CNTF in energy balance $(86,87)$. Mouse studies show that the antiobesogenic action of CNTF is largely leptin independent (88). Similarly to leptin, CNTF acts on hypothalamic neurons to decrease food intake and increase thermogenesis and UCP-1 gene expression in BAT $(88,89)$, and peripherally to promote AMPK (5' adenosine monophosphate-activated protein kinase)-dependent fatty acid oxidation (90). Differently from leptin, CNTF was also shown to induce COX-2 gene expression in brain vascular tissue (91). Thus, it is possible that CNTF, like other pyrogens, induces thermogenesis via COX-2dependent activation of the SNS. Indeed, the CNTF receptor CNTFR $\alpha$, similarly to IL-6 receptor, signals via gp130 protein and CNTF was also shown to bind to the IL-6 receptor (92-94); thus IL-6 and CNTF are recruiting distinct, but overlapping signalling networks.

\section{A possible role for leukocytes in thermogenesis and energy balance}

Overall the studies above suggest that the specific cytokine network recruited during obesity might have profound effects on energy balance. The obese WAT is characterized by leukocyte accumulation, polarization of resident macrophages towards a so-called M1 'pro-inflammatory' phenotype, and induction of pro-inflammatory cytokine gene expression including TNF $\alpha$, IL-1 and IL6. The specific impact of M1-activated pro-inflammatory macrophages on energy balance and thermogenesis during obesity remains to be established. However, it was recently reported that cold exposure induces alternative activation of macrophages towards an 'M2 anti-inflammatory' phenotype (95). Most notably, the authors show that mice with defective macrophage alternative M2 activation display cold intolerance, which was explained by defective lipolysis in WAT, depletion of BAT lipid storage, and decreased BAT activation. Thus the study mentioned earlier suggests an important role for alternatively activated M2 macrophages in the 
promotion of lipolysis and thermogenesis. By contrast, another study reported that during caloric restriction, a condition characterized by increased lipolysis and suppressed thermogenesis, macrophages accumulate to WAT to decrease glycerol and FFA efflux from lipolysis (96). Thus it will be important to test whether classically activated M1 'pro-inflammatory' macrophages and alternatively activated M2 'anti-inflammatory' macrophages play opposing roles in lipolysis and thermogenesis.

In addition to a possible role for macrophages in thermogenesis, it was shown that genetic deficiency or pharmacological stabilization of mast cells leads to decreased weight gain in a mouse model of diet-induced obesity (97). Whereas this study suggests a role for mast cells in the control of energy balance during obesity, it remains to be established whether mast cells modulate thermogenesis and feed efficiency rather than digestible energy intake.

Overall, the major pro-inflammatory cytokines induced during obesity have somehow been implicated in the control of thermogenesis and energy balance. A more detailed understanding of the specific cytokine network recruited during obesity and its action on thermogenesis and energy balance may thus be fundamental for novel strategies to treat or prevent obesity.

\section{The cyclooxygenase-2 in thermogenesis and energy balance}

Pyrogenic cytokines and exogenous pyrogens such as bacterial LPS are believed to activate the SNS and thermogenesis by a mechanism involving COX-2-mediated production of pyrogenic prostaglandins. A possible role for COX-2 in energy balance was suggested by a study showing that mice that are heterozygous for a COX-2 null mutation, with reduced COX-2 levels, display increased weight-gain and adiposity compared with control mice (98). Curiously, the same authors reported that mice bearing the COX-2 null mutation on both alleles, which did not express COX-2, showed similar body weight and adiposity compared with WT control mice. Furthermore, another study reported that whereas mice lacking COX-2 display similar body weight to WT control mice until the age of 6 months, by the age of 9 months mice lacking COX-2 gained much less weight that WT controls despite similar food consumption (99). These studies suggest that COX-2 may be implicated in the control of energy balance by a dose- and age-dependent mechanism.

Recently, COX-2 was implicated in cold-induced thermogenesis. Indeed two different laboratories reported that cold exposure leads to increased COX-2 expression in adipose tissue of mice, which correlate with the expression of markers for BAT differentiation $(100,101)$. This induction of COX-2 gene expression was recapitulated by treatment of mice with a $\beta 3$-adrenergic receptor agonist suggesting that cold-induced COX-2 gene expression is mediated by increased sympathetic activity. Mice lacking COX-2 activity were less able to maintain core body temperature in the cold and showed defective induction of markers for BAT differentiation in inguinal WAT compared with control mice expressing COX-2 (100,101). Importantly, mice treated with indomethacin, a non-selective COX inhibitor displayed increased weight gain and adiposity, despite the fact that energy intake was not increased compared with control mice (100). Furthermore, it was shown that mice overexpressing COX-2 in WAT gained less weight than control mice kept on either low-fat or HFD. Consistently, compared with WT control mice, the transgenic mice overexpressing COX-2 in WAT displayed elevated thermogenesis and induction of BAT differentiation within intra-abdominal WAT pads (101). Collectively, these studies strongly suggest that the sympathetic action in cold-induced thermogenesis is in part mediated by COX-2. Furthermore, COX-2 levels may play an important role in energy balance and body weight homeostasis.

\section{Obesity-activated pro-inflammatory signal transducers, their role in thermogenesis and diet-induced obesity}

\section{Metabolic inflammation, a possible mechanism for obesity-induced leptin resistance}

Obesity is characterized by hyperleptinaemia. While this suggests that excess adiposity may cause leptin resistance (102), the elevated leptin levels may also be part of a homeostatic reaction to the excessive caloric intake. In either case, insufficient leptin signalling may promote positive energy balance and diet-induced obesity via increased food consumption and impaired thermogenic response to excess caloric intake. Two major negative regulators of leptin signalling are the protein tyrosine phosphatase $1 \mathrm{~B}$ (PTP1B) and the suppressor of cytokine signalling 3 (SOCS3). Remarkably, mutant mice that do not express functional PTP1B in the brain or heterozygote mice for SOCS3 loss of function mutation are protected from dietinduced obesity and insulin resistance (103-107). Furthermore, a study showed that compared with control mice, double mutant mice, which do not express PTP1B and SOCS3 in neurons are resistant to diet-induced obesity largely because of increased thermogenesis (108). Metabolic inflammation emerged as a molecular mechanism for obesity-induced leptin resistance. Indeed, it was reported that PTP1B expression during obesity correlates with inflammation, and that TNF $\alpha$ increases PTP1B mRNA levels via activation of the transcription factor NF-kB (109). Similarly, it was shown that SOCS3 induction during obesity depends on NF-kB activation in neurons (110). These studies strongly suggest that the expression of major 


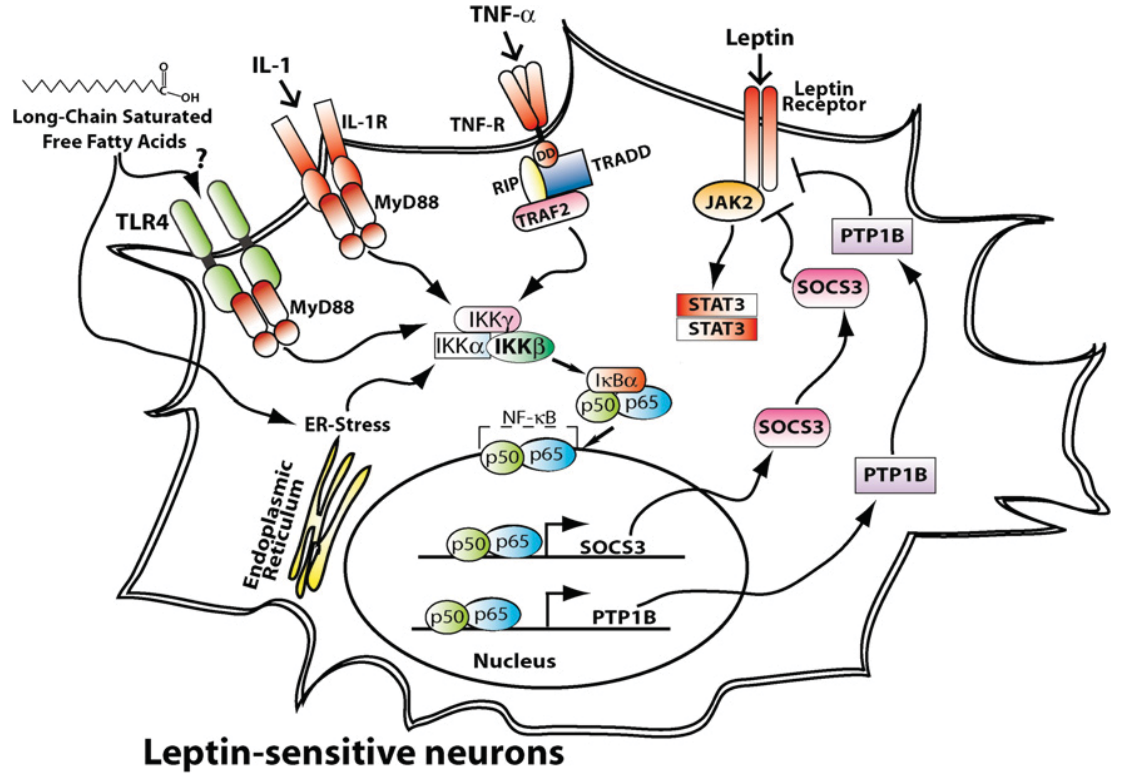

Figure 3 A possible inflammatory mechanism contributing to reduced leptin signalling. Obesity is characterized by hyperleptinaemia possibly consequent to leptin resistance. The suppressor of cytokine signalling (SOCS3) and the protein tyrosine phosphatase (PTP1B) were proposed to be important negative regulators of leptin signalling. During obesity cytokines (e.g. tumour necrosis factor- $\alpha$ [TNF $\alpha]$, and interleukin [IL]-1 $\beta$ ) and long-chain saturated fatty acids lead to the activation of the inhibitor of kappa-B kinase (IKK $\beta$ ) nuclear factor kappa-B (NF-kB) signalling cascade. NF-kB was shown to be a positive regulator of SOCS3 and PTP1B gene expression. Thus, during obesity, increased IKK $\beta$ signalling may promote leptin resistance by sustaining NF-kB dependent SOCS3 and PTP1B gene expression in leptin sensitive neurons. JAK, Janus kinase; TLR4, toll-like receptor 4 . negative regulators of leptin signalling, PTP1B and SOCS3, is induced by pro-inflammatory pathways recruited during obesity (Fig. 3).

\section{Myeloid differentiation primary response gene 88}

Myeloid differentiation primary response gene 88 (MYD88) is an adapter protein that functions as scaffold recruiting pro-inflammatory signal cascades downstream to IL-1R and TLR receptors. It was reported that mice lacking neuronal MyD88 are protected from diet-induced obesity and leptin resistance, and display decreased food intake and increased thermogenesis compared with control mice (111). The precise pathway linking neuronal MyD88 signalling to leptin resistance during obesity remains to be identified but it was proposed to be mediated by the protein kinase IKK $\beta$, the pro-inflammatory signal transducer responsible for the activation of NF-kB (Fig. 3).

\section{Inhibitor of nuclear factor kappa-B kinase- $\beta$}

IKK $\beta$ is part of the IKK complex, comprising the catalytic subunits IKK $\alpha$ and IKK $\beta$, and the regulatory protein IKK $\gamma$ (112). IKK $\beta$ is activated in response to several proinflammatory signals and is considered to play a major role in obesity-induced inflammation and insulin resistance (39). In acute inflammation, IKK $\beta$ acts as a sensor and a signal amplifier where cytokines and PAMPs such as IL-1, TNF $\alpha$ and LPS potently induce IKK $\beta$ activity resulting in increased NF-kB nuclear translocation and consequent induction of the expression of several inflammatory mediators including IL-1 and TNF $\alpha$ (112). It was shown that genetically modified mice that do not express IKK $\beta$ in neurons are protected from diet-induced obesity and leptin resistance compared with WT control mice (110). The resistance to diet-induced obesity in mice lacking neuronal IKK $\beta$ could be largely explained by decreased food intake consequent to improved leptin sensing within the hypothalamus. However, given the key role of leptin in diet-induced thermogenesis, it is possible that an improved thermogenic response to excess calories also contributes to the obesityresistant phenotype of mice with neuronal IKK $\beta$ inactivation. At the molecular level, it was proposed that in the obese hypothalamus, excess adiposity causes endoplasmic reticulum stress response activating the IKK $\beta$ NF-kB signalling pathway, which induces SOCS3 gene expression and thus leptin resistance $(110,113)$ (Fig. 3).

\section{The inhibitor of nuclear factor kappa-B kinase- $\varepsilon$}

The inhibitor of NF kappa-B kinase- $\varepsilon$ (IKKe) is a protein kinase whose expression is induced by NF-kB during inflammation and that was implicated in the regulation of NF-kB activity (112). It was proposed that IKKe plays an important role in energy balance during diet-induced obesity. Indeed, one study showed that mice lacking IKKE were protected in a model of diet-induced obesity because of increased thermogenesis, which was explained by increased expression of UCP-1 in WAT (114). The relative importance of IKKE in the promotion of diet-induced obesity was questioned by another study, as the impact of IKKe inactivation on diet-induced obesity may depend on the specific experimental condition (115). Still, the latter study supported the role of IKKe in the control of UCP-1 gene expression in WAT. Overall these studies suggest that $\mathrm{IKK} \varepsilon$ is a negative regulator of thermogenesis possibly by 
inhibiting brown adipocyte differentiation within WAT depots. The specific mechanism by which $\mathrm{IKK} \varepsilon$ regulates UCP-1 gene expression within WAT remains to be established, but it would be interesting to test whether IKKE controls COX-2 expression in WAT pads.

\section{c-Jun N-terminal kinases and other mitogen-activated protein kinases}

The c-Jun N-terminal kinases (JNK) is a member of the MAPK family, whose activity is induced in response to several pro-inflammatory and stress signals (116). JNK activity is chronically elevated during obesity in multiple tissues and the JNK1 and JNK2 isozymes emerged as major molecular links connecting obesity, inflammation and insulin resistance (39-41). Indeed mouse genetic studies showed that JNK1 and JNK2 play an important role in the promotion of diet-induced obesity $(117,118)$. The role of JNK1 in diet-induced obesity is largely leptin independent as leptin-deficient $o b / o b$ mice lacking a functional JNK1 display a leaner phenotype compared with ob/ob mice expressing JNK1 (118). Obesity resistance in mice lacking JNK1 is largely due to increased thermogenesis and depends on its activity within a non-haematopoietic compartment (119). Indeed, studies of mouse tissue-conditional JNK1 gene deletion showed that the brain is a main site for the obesogenic action of JNK1, and suggested that neuronal JNK1 negatively regulates hypothalamic-mediated induction of thyroid hormone release (120). Altogether, these studies support the hypothesis that neuronal JNK1 activity may promote positive energy balance and obesity by a mechanism involving negative regulation of thyroid hormone secretion.

JNK1 is not the only MAPK that has been implicated in diet-induced obesity. Indeed, it was reported that mice that do not express the extracellular-regulated kinase-1 (ERK1) are also resistant to diet-induced obesity and display exaggerated thermogenic response to food compared with control mice (121). As the loss of ERK1 did not reduce obesity in $o b / o b$ mice, the mechanism of action of ERK1 in diet-induced obesity depends on leptin signalling (122).

Another study implicated the MAPK p38 $\delta$ in obesityinduced glucose intolerance (123). Interestingly, mice that do not express $\mathrm{p} 38 \delta$ are partially protected from dietinduced obesity (123), although it remains to be established whether the role of $\mathrm{p} 38 \delta$ in diet-induced obesity is to control thermogenesis.

\section{The double-stranded RNA-dependent protein kinase}

The double-stranded RNA-dependent protein kinase (PKR) was proposed to play a major role in lipid-induced inflammation, JNK activation and insulin resistance (124). Mice bearing a targeted deletion at the PKR gene are protected from lipid-induced insulin resistance and HFD-induced glucose and insulin intolerance. Interestingly, mice that do not express PKR are dramatically protected from diet-induced obesity compared with WT control mice (124). PKR activity may promote food intake and decrease rate of oxygen consumption by a mechanism involving JNK activation (124). However, the precise molecular mechanism by which PKR controls energy balance during diet-induced obesity is still to be identified.

\section{The class IB phosphatidylinositide-3 kinase posphatidylinositide-3 kinase (PI3K- $\gamma$ )}

The phosphatidylinositide-3 kinase- $\gamma$ PI $3 \mathrm{~K} \gamma$ is the only member of class IB phosphatidylinositide- 3 kinase that, unlike the class IA PI3Ks, is not activated by receptor tyrosine kinases such as the insulin receptor, but is instead activated by several G-protein coupled receptors (125128). PI3K $\gamma$ signalling is recruited by receptors implicated in inflammation such as chemokine receptors and receptors involved in the control of energy balance and thermogenesis such as the angiotensin II AT1 receptors and $\beta$-adrenergic receptors (128-131). Because of its importance in chemokine signalling, PI $3 \mathrm{~K} \gamma$ plays a key role in inflammation by promoting leukocyte migration to the site of infection (128). Interestingly, PI3K $\gamma$ was also shown to be a negative regulator of $\beta$-adrenergic signalling in the cardiomyocytes $(132,133)$. The latter may be relevant to thermogenesis, as cold-induced and diet-induced thermogenesis depend on $\beta$-adrenergic signalling $(4,6)$ and both cold exposure and cafeteria diet increase norepinephrine turnover in the heart (9). It was recently proposed that PI3K $\gamma$ plays an important role in the link between obesity, inflammation and glucose intolerance $(55,134)$. Most notably, mice bearing a targeted gene deletion at the $P I 3 K \gamma$ locus are protected from diet-induced obesity because of decreased feed efficiency consequent to enhanced diet-induced thermogenesis (55). The precise molecular mechanism linking PI3K $\gamma$ to diet-induced thermogenesis remains to be identified; however, it may involve control of sympathetic signalling in the heart and lipolysis in WAT $(55,132,133)$. Furthermore, the effects of PI3K $\gamma$ inactivation on energy balance depends on leptin signalling as mice that do not express PI3K $\gamma$ are protected from obesity in dietary models, but not in the leptin-deficient ob/ob model $(55,134)$. Consistent with the data mentioned earlier, it was recently reported that mice overexpressing the phosphatase PTEN (phosphatase and tensin homolog), which counteracts the activity of class I PI3Ks, display decreased adiposity because of increased thermogenesis (135). Overall, these results suggest that the class IB PI3K $\gamma$ promote positive energy balance and diet-induced obesity via negative regulation of thermogenesis. 


\section{Final considerations}

Environmental temperature, diet (quality and quantity) and systemic inflammation are the three main factors modulating thermogenesis $(2,3)$. It is now established that obesity is characterized by a low-grade systemic chronic inflammation, which was proposed by several authors to trigger pathways promoting positive energy balance $(39,41,136$, 137). Here are reviewed the pathways that may be implicated in linking obesity-associated metabolic inflammation with thermogenesis and feed efficiency. Overall, a large body of evidence suggests that the cytokines and signalling molecules described in this review should be regarded as pleiotropic signal transducers which, on top of their function in innate immunity, also play an important role in body weight homeostasis (Figs 2 and 3, and Table 1). During systemic inflammation, complex signalling cascades are recruited, and each specific model of systemic inflammation is characterized by a specific signalling network. Obesity-induced inflammation is a peculiar inflammatory state characterized by chronic low-grade increased levels of several pro-inflammatory cytokines and a significant elevation of the levels of the anti-inflammatory IL-1Ra. Most inflammatory pathways recruited during obesity were proposed to promote positive energy balance and thus their inhibition may be beneficial for the treatment of obesity. However, some of the cytokines recruited during metabolic inflammation (e.g. IL-1, IL-18 and IL-6) as well as COX-2, may promote thermogenesis and negative energy balance, and thus could be protective towards the development of obesity $(68,71-77,100,101)$. It is concluded that a specific modulation of metabolic inflammation, rather than its suppression, could be a promising strategy for the prevention and treatment of obesity and related diseases. In support of this concept are studies showing that pharmacological administration of the pyrogen CNTF to rodents and humans leads to reduced body weight compared with controls $(86-89,138)$. CNTF can be seen as a paradigm of the pleiotropic nature of many cytokines; indeed it acts as a neuron-survival factor (84), an endogenous pyrogen (85), as well as an anorexigenic and thermogenic signal implicated in body weight homeostasis (88). There could be potential limitations and pitfalls in exploiting inflammatory pathways to treat obesity. The development of adverse effects may be a possible concern, and it is not clear to which extent it can be possible to achieve stable weight loss over a long period of time by such approaches. Thus, a better understanding of the role of metabolic inflammation in the control of body weight homeostasis is necessary. Of interest, some evidence suggests that metabolic inflamma-

Table 1 Possible roles of pro-inflammatory signal transducers recruited during obesity in energy balance and thermogenesis

\begin{tabular}{|c|c|c|c|}
\hline $\begin{array}{l}\text { Signal } \\
\text { transducer }\end{array}$ & Phenotype of mutant mouse in energy balance & Molecular mechanism or mechanistic insights & References \\
\hline MyD88 & $\begin{array}{l}\text { Mice lacking MyD88 in neurons display increased leptin } \\
\text { sensitivity. }\end{array}$ & $\begin{array}{l}\text { Neuronal MyD88 may be implicated in the development } \\
\text { of leptin resistance. }\end{array}$ & $(111)$ \\
\hline $\mathrm{IKK} \beta$ & $\begin{array}{l}\text { Mice lacking IKK } \beta \text { in neurons are resistant to } \\
\text { diet-induced obesity and display increased sensitivity to } \\
\text { leptin. }\end{array}$ & $\begin{array}{l}\text { IKK } \beta \text { activity in neurons may be implicated in leptin } \\
\text { resistance by sustaining NF-kB dependent SOCS3 and } \\
\text { PTP1B gene expression. }\end{array}$ & $(110)$ \\
\hline $\mathrm{IKK} \varepsilon$ & $\begin{array}{l}\text { Mice lacking IKKE display increased UCP-1 levels in } \\
\text { WAT and decreased weight gain in specific models. }\end{array}$ & $\begin{array}{l}\text { IKK } \varepsilon \text { could be implicated in the control of brown } \\
\text { adipocyte recruitment and activation within specific WAT } \\
\text { pads. }\end{array}$ & $(114,115)$ \\
\hline JNK1 & $\begin{array}{l}\text { Mice lacking JNK1 display an important } \\
\text { obesity-resistant phenotype largely due to increased } \\
\text { thermogenesis. }\end{array}$ & $\begin{array}{l}\text { JNK1 activity in neurons was proposed to be a negative } \\
\text { regulator of the hypothalamic-thyroid hormone axis. }\end{array}$ & $(117-120)$ \\
\hline ERK1 & $\begin{array}{l}\text { Mice lacking ERK1 are resistant to diet-induced obesity } \\
\text { and display increased thermogenic response to feeding. }\end{array}$ & $\begin{array}{l}\text { ERK1 may promote feeding efficiency via negative } \\
\text { regulation of the thermogenic response to feeding. }\end{array}$ & $(121,122)$ \\
\hline p38 & $\begin{array}{l}\text { Mice lacking p38 } \delta \text { display a partial protection from } \\
\text { diet-induced obesity. }\end{array}$ & $\begin{array}{l}\text { The mechanism of the leaner phenotype of mice lacking } \\
\text { p38 is unknown. }\end{array}$ & $(123)$ \\
\hline PKR & $\begin{array}{l}\text { Mice lacking PKR are largely resistant to diet-induced } \\
\text { obesity. }\end{array}$ & $\begin{array}{l}\text { The precise mechanism of action of PKR in diet-induced } \\
\text { obesity is to be established. However, PKR action could } \\
\text { be explained by JNK activation. }\end{array}$ & $(124)$ \\
\hline $\mathrm{PI} 3 \mathrm{~K} \gamma$ & $\begin{array}{l}\text { Mice lacking PI3K } \gamma \text { are largely resistant to diet-induced } \\
\text { obesity, display reduced feeding efficiency and } \\
\text { increased diet-induced thermogenesis. }\end{array}$ & $\begin{array}{l}\text { PI } 3 \mathrm{~K} \gamma \text { is a negative regulator of diet-induced } \\
\text { thermogenesis. The precise molecular mechanism is not } \\
\text { known, but may involve decreased PKA signalling in } \\
\text { WAT and in cardiomyocytes. }\end{array}$ & $(55,134)$ \\
\hline
\end{tabular}

ERK, extracellular-regulated kinase-1; IKK, inhibitor of kappa-B kinase; JNK, C-Jun N-terminal kinases; PKR, protein kinase; PTP1B, protein tyrosine phosphatase 1B; UCP-1, uncoupling protein; WAT, white adipose tissue. 
tion and thermogenesis could be modulated by nutrients $(139,140)$. In particular long-chain saturated fatty acids are considered to be a major cause of metabolic inflammation whereas some unsaturated fatty acids have been shown to be protective (141-145). Thus, for the future, in addition to a pharmacological approach, it will be important to investigate whether specific pathways linking metabolic inflammation and thermogenesis could be targeted by a nutraceutical strategy aimed at the prevention of obesity in overweight individuals as well as obesity relapse after therapeutic dieting.

\section{Conflict of interest statement}

The author declares that there is no conflict of interest for the field covered by this review.

\section{Acknowledgements}

G.S. is supported by grants from the Swiss National Science Foundation 31003A_135684) and the European Foundation for the Study of Diabetes (Diabetes and Cancer). Because of space limitation, references are limited to the one more essential for the focus of this review. I apologize for the many excellent works that are not cited here. I am grateful to Dr. Barbara Becattini of the University of Fribourg for her feedback on this paper.

\section{References}

1. Rothwell NJ, Stock MJ. Regulation of energy balance. Annu Rev Nutr 1981; 1: 235-256.

2. Stock MJ. Gluttony and thermogenesis revisited. Int J Obes Relat Metab Disord 1999; 23: 1105-1117.

3. Rothwell NJ. CNS regulation of thermogenesis. Crit Rev Neurobiol 1994; 8: 1-10.

4. Bachman ES, Dhillon $\mathrm{H}$, Zhang CY et al. betaAR signaling required for diet-induced thermogenesis and obesity resistance. Science 2002; 297: 843-845.

5. Jimenez M, Leger B, Canola K et al. Beta(1)/beta(2)/beta(3)adrenoceptor knockout mice are obese and cold-sensitive but have normal lipolytic responses to fasting. FEBS Lett 2002; 530: 37-40. 6. Lowell BB, Bachman ES. Beta-Adrenergic receptors, dietinduced thermogenesis, and obesity. J Biol Chem 2003; 278: 29385-29388.

7. Lowell BB, Spiegelman BM. Towards a molecular understanding of adaptive thermogenesis. Nature 2000; 404: 652-660.

8. Young JB, Weiss J, Boufath N. Effects of dietary monosaccharides on sympathetic nervous system activity in adipose tissues of male rats. Diabetes 2004; 53: 1271-1278.

9. Landsberg L, Saville ME, Young JB. Sympathoadrenal system and regulation of thermogenesis. Am J Physiol 1984; 247: E181E189.

10. Young JB, Landsberg L. Diminished sympathetic nervous system activity in genetically obese (ob/ob) mouse. Am J Physiol 1983; 245: E148-E154.

11. Collins S, Kuhn CM, Petro AE, Swick AG, Chrunyk BA, Surwit RS. Role of leptin in fat regulation. Nature 1996; 380: 677.
12. Trayhurn P, Jones PM, McGuckin MM, Goodbody AE. Effects of overfeeding on energy balance and brown fat thermogenesis in obese (ob/ob) mice. Nature 1982; 295: 323-325.

13. Trayhurn P, James WP. Thermoregulation and non-shivering thermogenesis in the genetically obese (ob/ob) mouse. Pflugers Arch 1978; 373: 189-193.

14. Steinman L. Elaborate interactions between the immune and nervous systems. Nat Immunol 2004; 5: 575-581.

15. Elenkov IJ, Wilder RL, Chrousos GP, Vizi ES. The sympathetic nerve an integrative interface between two supersystems: the brain and the immune system. Pharmacol Rev 2000; 52: 595638 .

16. Bergquist J, Tarkowski A, Ekman R, Ewing A. Discovery of endogenous catecholamines in lymphocytes and evidence for catecholamine regulation of lymphocyte function via an autocrine loop. Proc Natl Acad Sci U S A 1994; 91: 12912-12916.

17. Flierl MA, Rittirsch D, Nadeau BA et al. Phagocyte-derived catecholamines enhance acute inflammatory injury. Nature 2007; 449: 721-725.

18. Arsenijevic D, Onuma H, Pecqueur C et al. Disruption of the uncoupling protein- 2 gene in mice reveals a role in immunity and reactive oxygen species production. Nat Genet 2000; 26: 435-439. 19. Dinarello CA. Infection, fever, and exogenous and endogenous pyrogens: some concepts have changed. J Endotoxin Res 2004; 10: 201-222.

20. Leon LR. Cytokine regulation of fever: studies using gene knockout mice. J Appl Physiol 2002; 92: 2648-2655.

21. Saper CB. Neurobiological basis of fever. Ann N Y Acad Sci 1998; 856: 90-94.

22. Luheshi GN. Cytokines and fever. Mechanisms and sites of action. Ann N Y Acad Sci 1998; 856: 83-89.

23. Akira S. TLR signaling. Curr Top Microbiol Immunol 2006; 311: $1-16$.

24. Li S, Ballou LR, Morham SG, Blatteis CM. Cyclooxygenase-2 mediates the febrile response of mice to interleukin-1beta. Brain Res 2001; 910: 163-173.

25. Li S, Wang Y, Matsumura K, Ballou LR, Morham SG, Blatteis $\mathrm{CM}$. The febrile response to lipopolysaccharide is blocked in cyclooxygenase-2(-/-), but not in cyclooxygenase-1(-/-) mice. Brain Res 1999; 825: 86-94.

26. Jepson MM, Millward DJ, Rothwell NJ, Stock MJ. Involvement of sympathetic nervous system and brown fat in endotoxininduced fever in rats. Am J Physiol 1988; 255: E617-E620.

27. Dascombe MJ, Rothwell NJ, Sagay BO, Stock MJ. Pyrogenic and thermogenic effects of interleukin 1 beta in the rat. Am J Physiol 1989; 256: E7-11.

28. Leon LR. Hypothermia in systemic inflammation: role of cytokines. Front Biosci 2004; 9: 1877-1888.

29. Romanovsky AA, Almeida MC, Aronoff DM et al. Fever and hypothermia in systemic inflammation: recent discoveries and revisions. Front Biosci 2005; 10: 2193-2216.

30. Roth J. Endogenous antipyretics. Clin Chim Acta 2006; 371: 13-24.

31. Rothwell NJ. Central effects of TNF alpha on thermogenesis and fever in the rat. Biosci Rep 1988; 8: 345-352.

32. Coombes RC, Rothwell NJ, Shah P, Stock MJ. Changes in thermogenesis and brown fat activity in response to tumour necrosis factor in the rat. Biosci Rep 1987; 7: 791-799.

33. Dinarello CA, Cannon JG, Wolff SM et al. Tumor necrosis factor (cachectin) is an endogenous pyrogen and induces production of interleukin 1. J Exp Med 1986; 163: 1433-1450.

34. Long NC, Kunkel SL, Vander AJ, Kluger MJ. Antiserum against tumor necrosis factor enhances lipopolysaccharide fever in rats. Am J Physiol 1990; 258: R332-R337. 
35. Long NC, Morimoto A, Nakamori T, Murakami N. Systemic injection of TNF-alpha attenuates fever due to IL-1 beta and LPS in rats. Am J Physiol 1992; 263: R987-R991.

36. Tollner B, Roth J, Storr B, Martin D, Voigt K, Zeisberger E. The role of tumor necrosis factor (TNF) in the febrile and metabolic responses of rats to intraperitoneal injection of a high dose of lipopolysaccharide. Pflugers Arch 2000; 440: 925-932.

37. Holt SJ, Grimble RF, York DA. Tumour necrosis factor-alpha and lymphotoxin have opposite effects on sympathetic efferent nerves to brown adipose tissue by direct action in the central nervous system. Brain Res 1989; 497: 183-186.

38. Olefsky JM, Glass CK. Macrophages, inflammation, and insulin resistance. Annu Rev Physiol 2010; 72: 219-246.

39. Solinas G, Karin M. JNK1 and IKKbeta: molecular links between obesity and metabolic dysfunction. FASEB J 2010; 24: 2596-2611.

40. Lumeng CN, Saltiel AR. Inflammatory links between obesity and metabolic disease. J Clin Invest 2011; 121: 2111-2117.

41. Gregor MF, Hotamisligil GS. Inflammatory mechanisms in obesity. Annu Rev Immunol 2011; 29: 415-445.

42. Donath MY, Shoelson SE. Type 2 diabetes as an inflammatory disease. Nat Rev Immunol 2011; 11: 98-107.

43. Chawla A, Nguyen KD, Goh YP. Macrophage-mediated inflammation in metabolic disease. Nat Rev Immunol 2011; 11: 738-749.

44. Ley RE, Backhed F, Turnbaugh P, Lozupone CA, Knight RD, Gordon JI. Obesity alters gut microbial ecology. Proc Natl Acad Sci U S A 2005; 102: 11070-11075.

45. Cani PD, Amar J, Iglesias MA et al. Metabolic endotoxemia initiates obesity and insulin resistance. Diabetes 2007; 56: 17611772.

46. Unger RH. Minireview: weapons of lean body mass destruction: the role of ectopic lipids in the metabolic syndrome. Endocrinology 2003; 144: 5159-5165.

47. Savage DB, Petersen KF, Shulman GI. Disordered lipid metabolism and the pathogenesis of insulin resistance. Physiol Rev 2007; 87: 507-520.

48. Virtue S, Vidal-Puig A. It's not how fat you are, it's what you do with it that counts. Plos Biol 2008; 6: e237.

49. Cinti S, Mitchell G, Barbatelli G et al. Adipocyte death defines macrophage localization and function in adipose tissue of obese mice and humans. J Lipid Res 2005; 46: 2347-2355.

50. Medina-Gomez G, Gray SL, Yetukuri L et al. PPAR gamma 2 prevents lipotoxicity by controlling adipose tissue expandability and peripheral lipid metabolism. Plos Genet 2007; 3: e64.

51. Lumeng CN, Deyoung SM, Bodzin JL, Saltiel AR. Increased inflammatory properties of adipose tissue macrophages recruited during diet-induced obesity. Diabetes 2007; 56: 16-23.

52. Lumeng CN, Bodzin JL, Saltiel AR. Obesity induces a phenotypic switch in adipose tissue macrophage polarization. J Clin Invest 2007; 117: 175-184.

53. Juge-Aubry CE, Somm E, Giusti V et al. Adipose tissue is a major source of interleukin-1 receptor antagonist: upregulation in obesity and inflammation. Diabetes 2003; 52: 1104-1110.

54. Dayer JM, Chicheportiche R, Juge-Aubry C, Meier C. Adipose tissue has anti-inflammatory properties: focus on IL-1 receptor antagonist (IL-1Ra). Ann N Y Acad Sci 2006; 1069: 444-453.

55. Becattini B, Marone R, Zani F et al. PI3Kgamma within a nonhematopoietic cell type negatively regulates diet-induced thermogenesis and promotes obesity and insulin resistance. Proc Natl Acad Sci U S A 2011; 108: E854-E863.

56. Backhed F, Ding H, Wang T et al. The gut microbiota as an environmental factor that regulates fat storage. Proc Natl Acad Sci U S A 2004; 101: 15718-15723.
57. Shi H, Kokoeva MV, Inouye K, Tzameli I, Yin H, Flier JS. TLR4 links innate immunity and fatty acid-induced insulin resistance. J Clin Invest 2006; 116: 3015-3025.

58. Tsukumo DM, Carvalho-Filho MA, Carvalheira JB et al. Loss-of-function mutation in Toll-like receptor 4 prevents dietinduced obesity and insulin resistance. Diabetes 2007; 56: 19861998.

59. Poggi M, Bastelica D, Gual P et al. $\mathrm{C} 3 \mathrm{H} / \mathrm{HeJ}$ mice carrying a toll-like receptor 4 mutation are protected against the development of insulin resistance in white adipose tissue in response to a highfat diet. Diabetologia 2007; 50: 1267-1276.

60. Elinav E, Strowig T, Henao-Mejia J, Flavell RA. Regulation of the antimicrobial response by NLR proteins. Immunity 2011; 34: 665-679.

61. Schertzer JD, Tamrakar AK, Magalhaes JG et al. NOD1 activators link innate immunity to insulin resistance. Diabetes 2011; 60: 2206-2215.

62. Sutterwala FS, Ogura Y, Flavell RA. The inflammasome in pathogen recognition and inflammation. J Leukoc Biol 2007; 82: 259-264.

63. Hoffman HM, Rosengren S, Boyle DL et al. Prevention of cold-associated acute inflammation in familial cold autoinflammatory syndrome by interleukin-1 receptor antagonist. Lancet 2004; 364: 1779-1785.

64. Neven B, Prieur AM, Quartier dit Maire P. Cryopyrinopathies: update on pathogenesis and treatment. Nat Clin Pract Rheumatol 2008; 4: 481-489.

65. Vandanmagsar B, Youm YH, Ravussin A et al. The NLRP3 inflammasome instigates obesity-induced inflammation and insulin resistance. Nat Med 2010; 17: 179-188.

66. Stienstra R, van Diepen JA, Tack CJ et al. Inflammasome is a central player in the induction of obesity and insulin resistance. Proc Natl Acad Sci U S A 2011; 108: 15324-15329.

67. Henao-Mejia J, Elinav E, Jin C et al. Inflammasome-mediated dysbiosis regulates progression of NAFLD and obesity. Nature 2012; 482: 179-185.

68. Wallenius V, Wallenius $\mathrm{K}$, Ahren B et al. Interleukin-6deficient mice develop mature-onset obesity. Nat Med 2002; 8: $75-79$.

69. Wernstedt I, Edgley A, Berndtsson A et al. Reduced stress- and cold-induced increase in energy expenditure in interleukin-6deficient mice. Am J Physiol Regul Integr Comp Physiol 2006; 291: R551-R557.

70. Di Gregorio GB, Hensley L, Lu T, Ranganathan G, Kern PA. Lipid and carbohydrate metabolism in mice with a targeted mutation in the IL-6 gene: absence of development of age-related obesity. Am J Physiol Endocrinol Metab 2004; 287: E182-E187. 71. Chida D, Osaka T, Hashimoto O, Iwakura Y. Combined interleukin-6 and interleukin-1 deficiency causes obesity in young mice. Diabetes 2006; 55: 971-977.

72. Luheshi GN, Gardner JD, Rushforth DA, Loudon AS, Rothwell NJ. Leptin actions on food intake and body temperature are mediated by IL-1. Proc Natl Acad Sci U S A 1999; 96: 7047-7052. 73. Somm E, Henrichot E, Pernin A et al. Decreased fat mass in interleukin-1 receptor antagonist-deficient mice: impact on adipogenesis, food intake, and energy expenditure. Diabetes 2005; 54: 3503-3509.

74. Chida D, Hashimoto O, Kuwahara M et al. Increased fat: carbohydrate oxidation ratio in Il1ra (-/-) mice on a high-fat diet is associated with increased sympathetic tone. Diabetologia 2008; 51: 1698-1706.

75. Garcia MC, Wernstedt I, Berndtsson A et al. Mature-onset obesity in interleukin-1 receptor I knockout mice. Diabetes 2006; 55: 1205-1213. 
76. Zorrilla EP, Sanchez-Alavez M, Sugama S et al. Interleukin-18 controls energy homeostasis by suppressing appetite and feed efficiency. Proc Natl Acad Sci U S A 2007; 104: 11097-11102. 77. Netea MG, Joosten LA, Lewis E et al. Deficiency of interleukin-18 in mice leads to hyperphagia, obesity and insulin resistance. Nat Med 2006; 12: 650-656.

78. Uysal KT, Wiesbrock SM, Marino MW, Hotamisligil GS. Protection from obesity-induced insulin resistance in mice lacking TNF-alpha function. Nature 1997; 389: 610-614.

79. Hotamisligil GS, Shargill NS, Spiegelman BM. Adipose expression of tumor necrosis factor-alpha: direct role in obesitylinked insulin resistance. Science 1993; 259: 87-91.

80. Nisoli E, Briscini L, Giordano A et al. Tumor necrosis factor alpha mediates apoptosis of brown adipocytes and defective brown adipocyte function in obesity. Proc Natl Acad Sci U S A 2000; 97: 8033-8038.

81. Romanatto T, Roman EA, Arruda AP et al. Deletion of tumor necrosis factor-alpha receptor 1 (TNFR1) protects against dietinduced obesity by means of increased thermogenesis. J Biol Chem 2009; 284: 36213-36222.

82. Allen TL, Matthews VB, Febbraio MA. Overcoming insulin resistance with ciliary neurotrophic factor. Handb Exp Pharmacol 2011; 203: 179-199.

83. Matthews VB, Febbraio MA. CNTF: a target therapeutic for obesity-related metabolic disease? J Mol Med (Berl) 2008; 86 353-361.

84. Adler R, Landa KB, Manthorpe M, Varon S. Cholinergic neuronotrophic factors: intraocular distribution of trophic activity for ciliary neurons. Science 1979; 204: 1434-1436.

85. Shapiro L, Zhang XX, Rupp RG, Wolff SM, Dinarello CA. Ciliary neurotrophic factor is an endogenous pyrogen. Proc Natl Acad Sci U S A 1993; 90: 8614-8618.

86. ALS CNTF Treatment Study Group. A double-blind placebocontrolled clinical trial of subcutaneous recombinant human ciliary neurotrophic factor ( $\mathrm{rHCNTF}$ ) in amyotrophic lateral sclerosis. Neurology 1996; 46: 1244-1249.

87. Miller RG, Petajan JH, Bryan WW et al. A placebo-controlled trial of recombinant human ciliary neurotrophic (rhCNTF) factor in amyotrophic lateral sclerosis. rhCNTF ALS Study Group. Ann Neurol 1996; 39: 256-260.

88. Gloaguen I, Costa P, Demartis A et al. Ciliary neurotrophic factor corrects obesity and diabetes associated with leptin deficiency and resistance. Proc Natl Acad Sci U S A 1997; 94: 64566461.

89. Bluher S, Moschos S, Bullen J Jr et al. Ciliary neurotrophic factorAx15 alters energy homeostasis, decreases body weight, and improves metabolic control in diet-induced obese and UCP1-DTA mice. Diabetes 2004; 53: 2787-2796.

90. Watt MJ, Dzamko N, Thomas WG et al. CNTF reverses obesity-induced insulin resistance by activating skeletal muscle AMPK. Nat Med 2006; 12: 541-548.

91. Kelly JF, Elias CF, Lee CE et al. Ciliary neurotrophic factor and leptin induce distinct patterns of immediate early gene expression in the brain. Diabetes 2004; 53: 911-920.

92. Ip NY, Nye SH, Boulton TG et al. CNTF and LIF act on neuronal cells via shared signaling pathways that involve the IL-6 signal transducing receptor component gp130. Cell 1992; 69: 1121-1132.

93. Schuster B, Kovaleva M, Sun Y et al. Signaling of human ciliary neurotrophic factor (CNTF) revisited. The interleukin-6 receptor can serve as an alpha-receptor for CTNF. J Biol Chem 2003; 278: 9528-9535.

94. Davis S, Aldrich TH, Valenzuela DM et al. The receptor for ciliary neurotrophic factor. Science 1991; 253: 59-63.
95. Nguyen KD, Qiu Y, Cui X et al. Alternatively activated macrophages produce catecholamines to sustain adaptive thermogenesis. Nature 2011; 480: 104-108.

96. Kosteli A, Sugaru E, Haemmerle G et al. Weight loss and lipolysis promote a dynamic immune response in murine adipose tissue. J Clin Invest 2010; 120: 3466-3479.

97. Liu J, Divoux A, Sun J et al. Genetic deficiency and pharmacological stabilization of mast cells reduce diet-induced obesity and diabetes in mice. Nat Med 2009; 15: 940-945.

98. Fain JN, Ballou LR, Bahouth SW. Obesity is induced in mice heterozygous for cyclooxygenase-2. Prostaglandins Other Lipid Mediat 2001; 65: 199-209.

99. Ghoshal S, Trivedi DB, Graf GA, Loftin CD. Cyclooxygenase-2 deficiency attenuates adipose tissue differentiation and inflammation in mice. J Biol Chem 2011; 286: 889898.

100. Madsen L, Pedersen LM, Lillefosse HH et al. UCP1 induction during recruitment of brown adipocytes in white adipose tissue is dependent on cyclooxygenase activity. Plos ONE 2010; 5: e11391.

101. Vegiopoulos A, Muller-Decker K, Strzoda D et al. Cyclooxygenase- 2 controls energy homeostasis in mice by de novo recruitment of brown adipocytes. Science 2010; 328: 1158-1161. 102. Frederich RC, Hamann A, Anderson S, Lollmann B, Lowell BB, Flier JS. Leptin levels reflect body lipid content in mice: evidence for diet-induced resistance to leptin action. Nat Med 1995; 1: 1311-1314.

103. Bjorbaek C, Elmquist JK, Frantz JD, Shoelson SE, Flier JS. Identification of SOCS-3 as a potential mediator of central leptin resistance. Mol Cell 1998; 1: 619-625.

104. Howard JK, Cave BJ, Oksanen LJ, Tzameli I, Bjorbaek C, Flier JS. Enhanced leptin sensitivity and attenuation of dietinduced obesity in mice with haploinsufficiency of Socs3. Nat Med 2004; 10: 734-738.

105. Bence KK, Delibegovic M, Xue B et al. Neuronal PTP1B regulates body weight, adiposity and leptin action. Nat Med 2006; 12: 917-924.

106. Cheng A, Uetani N, Simoncic PD et al. Attenuation of leptin action and regulation of obesity by protein tyrosine phosphatase 1B. Dev Cell 2002; 2: 497-503.

107. Elchebly M, Payette P, Michaliszyn E et al. Increased insulin sensitivity and obesity resistance in mice lacking the protein tyrosine phosphatase-1B gene. Science 1999; 283: 1544 1548 .

108. Briancon N, McNay DE, Maratos-Flier E, Flier JS. Combined neural inactivation of suppressor of cytokine signaling-3 and protein-tyrosine phosphatase-1B reveals additive, synergistic, and factor-specific roles in the regulation of body energy balance. Diabetes 2010; 59: 3074-3084.

109. Zabolotny JM, Kim YB, Welsh LA, Kershaw EE, Neel BG, Kahn BB. Protein-tyrosine phosphatase 1B expression is induced by inflammation in vivo. J Biol Chem 2008; 283: 14230-14241. 110. Zhang X, Zhang G, Zhang H, Karin M, Bai H, Hypothalamic CD. IKKbeta/NF-kappaB and ER stress link overnutrition to energy imbalance and obesity. Cell 2008; 135: 61-73.

111. Kleinridders A, Schenten D, Konner AC et al. MyD88 signaling in the CNS is required for development of fatty acid-induced leptin resistance and diet-induced obesity. Cell Metab 2009; 10: 249-259.

112. Hacker H, Karin M. Regulation and function of IKK and IKK-related kinases. Sci STKE 2006; 2006: re13.

113. Ozcan L, Ergin AS, Lu A et al. Endoplasmic reticulum stress plays a central role in development of leptin resistance. Cell Metab 2009; 9: 35-51. 
114. Chiang SH, Bazuine M, Lumeng $\mathrm{CN}$ et al. The protein kinase IKKepsilon regulates energy balance in obese mice. Cell 2009; 138: 961-975.

115. Scheja L, Heese B, Seedorf K. Beneficial effects of IKKepsilon-deficiency on body weight and insulin sensitivity are lost in high fat diet-induced obesity in mice. Biochem Biophys Res Commun 2011; 407: 288-294.

116. Karin M, Gallagher E. From JNK to pay dirt: jun kinases, their biochemistry, physiology and clinical importance. IUBMB Life 2005; 57: 283-295.

117. Tuncman G, Hirosumi J, Solinas G, Chang L, Karin M, Hotamisligil GS. Functional in vivo interactions between JNK1 and JNK2 isoforms in obesity and insulin resistance. Proc Natl Acad Sci U S A 2006; 103: 10741-10746.

118. Hirosumi J, Tuncman G, Chang L et al. A central role for JNK in obesity and insulin resistance. Nature 2002; 420: 333-336.

119. Solinas G, Vilcu C, Neels JG et al. JNK1 in hematopoietically derived cells contributes to diet-induced inflammation and insulin resistance without affecting obesity. Cell Metab 2007; 6: 386397.

120. Sabio G, Cavanagh-Kyros J, Barrett $\mathrm{T}$ et al. Role of the hypothalamic-pituitary-thyroid axis in metabolic regulation by JNK1. Genes Dev 2010; 24: 256-264.

121. Bost F, Aouadi M, Caron L et al. The extracellular signalregulated kinase isoform ERK1 is specifically required for in vitro and in vivo adipogenesis. Diabetes 2005; 54: 402-411.

122. Jager J, Corcelle V, Gremeaux T et al. Deficiency in the extracellular signal-regulated kinase 1 (ERK1) protects leptindeficient mice from insulin resistance without affecting obesity. Diabetologia 2011; 54: 180-189.

123. Sumara G, Formentini I, Collins S et al. Regulation of PKD by the MAPK p38delta in insulin secretion and glucose homeostasis. Cell 2009; 136: 235-248.

124. Nakamura T, Furuhashi M, Li P et al. Double-stranded RNA-dependent protein kinase links pathogen sensing with stress and metabolic homeostasis. Cell 2010; 140: 338-348.

125. Jia S, Liu Z, Zhang S et al. Essential roles of PI(3)K-p110beta in cell growth, metabolism and tumorigenesis. Nature 2008; 454 . 776-779.

126. Ciraolo E, Iezzi M, Marone $\mathrm{R}$ et al. Phosphoinositide 3-kinase p110beta activity: key role in metabolism and mammary gland cancer but not development. Sci Signal 2008; 1: ra3.

127. Foukas LC, Claret M, Pearce W et al. Critical role for the p110alpha phosphoinositide-3-OH kinase in growth and metabolic regulation. Nature 2006; 441: 366-370.

128. Hirsch E, Katanaev VL, Garlanda C et al. Central role for G protein-coupled phosphoinositide 3-kinase gamma in inflammation. Science 2000; 287: 1049-1053.

129. Quignard JF, Mironneau J, Carricaburu V et al. Phosphoinositide 3-kinase gamma mediates angiotensin II-induced stimulation of L-type calcium channels in vascular myocytes. J Biol Chem 2001; 276: 32545-32551.
130. Naga Prasad SV, Barak LS, Rapacciuolo A, Caron MG, Rockman HA. Agonist-dependent recruitment of phosphoinositide 3-kinase to the membrane by beta-adrenergic receptor kinase 1 . A role in receptor sequestration. J Biol Chem 2001; 276: 1895318959.

131. Vecchione C, Patrucco E, Marino G et al. Protection from angiotensin II-mediated vasculotoxic and hypertensive response in mice lacking PI3Kgamma. J Exp Med 2005; 201: 1217-1228.

132. Crackower MA, Oudit GY, Kozieradzki I et al. Regulation of myocardial contractility and cell size by distinct PI3K-PTEN signaling pathways. Cell 2002; 110: 737-749.

133. Patrucco E, Notte A, Barberis L et al. PI3Kgamma modulates the cardiac response to chronic pressure overload by distinct kinase-dependent and -independent effects. Cell 2004; 118: 375387.

134. Kobayashi N, Ueki K, Okazaki Y et al. Blockade of class IB phosphoinositide-3 kinase ameliorates obesity-induced inflammation and insulin resistance. Proc Natl Acad Sci U S A 2011; 14: 5753-5758.

135. Ortega-Molina A, Efeyan A, Lopez-Guadamillas E et al. Pten positively regulates brown adipose function, energy expenditure, and longevity. Cell Metab 2012; 15: 382-394.

136. Arruda AP, Milanski M, Velloso LA. Hypothalamic inflammation and thermogenesis: the brown adipose tissue connection. J Bioenerg Biomembr 2011; 43: 53-58.

137. Konner AC, Bruning JC. Toll-like receptors: linking inflammation to metabolism. Trends Endocrinol Metab 2011; 22: 16-23. 138. Ettinger MP, Littlejohn TW, Schwartz SL et al. Recombinant variant of ciliary neurotrophic factor for weight loss in obese adults: a randomized, dose-ranging study. JAMA 2003; 289: 1826-1832.

139. Kim MS, Lee MS, Kown DY. Inflammation-mediated obesity and insulin resistance as targets for nutraceuticals. Ann N Y Acad Sci 2011; 1229: 140-146.

140. Dulloo AG. The search for compounds that stimulate thermogenesis in obesity management: from pharmaceuticals to functional food ingredients. Obes Rev 2011; 12: 866-883.

141. Solinas G, Naugler W, Galimi F, Lee MS, Karin M. Saturated fatty acids inhibit induction of insulin gene transcription by JNKmediated phosphorylation of insulin-receptor substrates. Proc Natl Acad Sci U S A 2006; 108: E854-E863.

142. Jaeschke A, Davis RJ. Metabolic stress signaling mediated by mixed-lineage kinases. Mol Cell 2007; 27: 498-508.

143. Holzer RG, Park EJ, Li N et al. Saturated fatty acids induce c-Src clustering within membrane subdomains, leading to JNK activation. Cell 2011; 147: 173-184.

144. Oh DY, Talukdar S, Bae EJ et al. GPR120 is an omega-3 fatty acid receptor mediating potent anti-inflammatory and insulin-sensitizing effects. Cell 2010; 142: 687-698.

145. Cao H, Gerhold K, Mayers JR, Wiest MM, Watkins SM, Hotamisligil GS. Identification of a lipokine, a lipid hormone linking adipose tissue to systemic metabolism. Cell 2008; 134: 933-944. 